\title{
Corporeidade: o legado de Marcel Mauss e Maurice Merleau-Ponty
}

Jocimar Daolio* , Ana Carolina Capellini Rigoni** , Odilon José Roble***

\section{Resumo}

O objetivo deste artigo é realizar um diálogo entre as contribuições de Marcel Mauss e Maurice Merleau-Ponty, no que diz respeito às reflexões elaboradas por ambos sobre o corpo e a corporeidade. Embora a base teórica do primeiro seja a antropologia e a do segundo, a fenomenologia, ambos se preocuparam em superar a famosa dicotomia inaugurada por Descartes entre pensamento e matéria. O texto busca, além de apontar as aproximações teóricas dos dois autores, mostrar a possibilidade de diálogo entre suas concepções. Procuramos demonstrar que o diálogo entre os autores é possível não só por suas diferenças, mas também por suas semelhanças. Para isso, trazemos algumas contribuições de estudiosos e pesquisadores que, baseados nos autores trabalhados ou em ideias semelhantes, objetivam ampliar a discussão sobre corpo e corporeidade na sociedade contemporânea.

\section{Palavras-chave}

corporeidade; Marcel Mauss; Merleau-Ponty.
* Professor da Faculdade de Educação Física da Unicamp, Campinas, SP, Brasil. jocimar@fef.unicamp.br

* * Doutoranda da Faculdade de Educação Física da Unicamp, Campinas, SP, Brasil. anacarolinarigoni@ yahoo.com.br

*** Professor da Faculdade de Educação Física da Unicamp, Campinas, SP, Brasil. roble@fef.unicamp.br 


\title{
Corporeity: the legacy of Marcel Mauss and Maurice Merleau-Ponty
}

\begin{abstract}
The purpose of this article is to make a dialogue between Marcel Mauss and Maurice Merleau-Ponty's contributions in respect to the reflections produced by both of them about body and corporeity. Although the theoretical basis for the first one is anthropology and for the second, phenomenology, both of them were concerned about overcoming the famous dichotomy inaugurated by Descartes between thinking and matter. The text seeks, while pointing out the theoretical approaches from both authors, to show the possibility of dialogue between their views. Our intention was to show that the dialogue between the authors is possible not only by their differences, but also by their similarities. To do so, we bring some contributions from scholars and researchers who, based on the studied authors or on similar ideas, seek to amplify the discussion about body and corporeity in contemporary society.
\end{abstract}

Key words corporeity; Marcel Mauss; Merleau-Ponty. 


\section{Introdução}

O objetivo deste trabalho é traçar um paralelo entre as contribuições de Marcel Mauss e Maurice Merleau-Ponty, no que diz respeito às reflexões elaboradas por ambos sobre o corpo e a corporeidade. 0 primeiro, sociólogo/antropólogo francês, considerado um dos pais da Antropologia Social contemporânea; e o segundo, também francês, filósofo, considerado um dos maiores representantes da fenomenologia. Os dois estudiosos se preocuparam em superar a famosa dicotomia inaugurada por Descartes entre pensamento e matéria. Ambos se empenharam em discutir e praticar uma ciência que avançasse do tradicional modelo utilizado pelas ciências naturais para outro que fosse capaz de contribuir para a criação das ciências do homem.

Marcel Mauss (1872-1950), sobrinho de Durkheim, com quem trabalhou até a morte deste, em 1917, partilhava as ideias do tio, para o qual a criação de uma ciência social dependia de olhar para os fatos sociais como coisas, a fim de serem comparados com outros fenômenos próprios da vida em sociedade. Tanto para Durkheim como para Mauss era necessária a sistematização de uma abordagem que desse conta da análise do homem não como resultado de estados individuais de consciência, nem como fruto de observação da sociedade como um conjunto de hábitos exóticos. Foi nesse sentido que Mauss organizou suas reflexões a respeito do ser humano, e foi nesta direção que ele elaborou noções como a de Fato Social Total, Homem Total, Dádiva, Técnicas do Corpo e outras ainda. Pensando com base num referencial sociológico, o autor se baseou principalmente em noções como as de "tradição" e de "hábitos" para explicar os modos como os indivíduos "fazem usos de seus corpos".

Maurice Merleau-Ponty (1908-1961) criticou o chamado pensamento de sobrevoo, fundado por Descartes como consequência da cisão consciência-mundo. Para Merleau-Ponty, esta cisão originou tanto o subjetivismo filosófico como o objetivismo científico. No primeiro caso, converteu o mundo numa representação dele próprio, valorizando a atitude consciente e distanciada do observador em relação aos objetos. No segundo caso, reduziu o objeto às suas propriedades específicas, como se, para sua compreensão, fossem necessárias unicamente a descrição e a observação de suas características, conforme tentado pelas ciências naturais (Chaui, 1980). Merleau-Ponty foi reconhecido como fenomenólogo, principalmente por suas teorias a respeito da percepção do homem. 0 autor

1. Termo utilizado pelo autor em seu texto As técnicas do corpo, ao afirmar que o corpo é o primeiro e mais importante instrumento do homem. Para além de uma visão utilitarista, à qual o termo possa remeter, Mauss tinha a intenção de demonstrar como nossas técnicas corporais são tradicionais e nossos gestos nada têm de naturais, mas são produzidos por "normas coletivas". 
direciona seus estudos baseado na ideia de que o corpo é a condição primeira do ser humano, e, portanto, é por meio dele que tomamos consciência do nosso modo de estar no mundo.

Comentando sobre a visão da escola francesa em relação ao acesso ao outro, Merleau-Ponty afirma:

[...] a escola francesa falhava no acesso ao outro que, não obstante, é a própria definição da sociologia. Como compreender o outro sem sacrificá-lo à nossa lógica e sem sacrificá-la a ele? Assimilando muito depressa o real a nossas idéias ou, então, declarando-o impermeável, a sociologia falava como se pudesse sobrevoar seu objeto e o sociólogo era um observador absoluto. Faltava uma penetração paciente no objeto e a comunicação com ele (Merleau-Ponty, 1980, p.194).

Para o autor, não há um observador absoluto, nem na sociologia de Durkheim, nem na psicanálise de Freud - ambas, em boa parte, desenvolvidas nas primeiras décadas do século XX. Da mesma forma, não há um objeto absoluto. Merleau-Ponty pondera sobre isso por meio do exemplo de uma casa.

[...] a casa ela mesma não é a casa vista de nenhum lugar, mas a casa vista de todas as partes. 0 objeto acabado é translúcido, é penetrado de todos os lados por uma infinidade atual de olhares que se recortam em sua profundidade e não deixam nada escondido aí (Merleau-Ponty, 1971, p.82).

Em outros termos, o que o autor está afirmando é que o objeto não existe por si só, mas depende da forma como é visto e apreendido pelas pessoas. A casa não é definida pela soma de suas características objetivas, mas pela quantidade de olhares sobre ela.

Esse movimento de crítica ao pensamento de sobrevoo da ciência, de certa forma, também é encontrado na obra de Mauss. Embora concordando com Durkheim que o fato social deveria ser visto como "coisa” e que era irredutível à explicação em nível psicológico, Mauss acreditava que o fato social só poderia ser completamente compreendido, se observado em sua incorporação numa experiência individual. Em outras palavras, os costumes de um povo estariam "encarnados" em cada indivíduo 
membro desse povo, e só através de sua unidade, tal como incorporada na experiência individual, é que poderiam ser compreendidos.

Nesse sentido, embora abordando a teoria dos autores de modo geral, atentaremos para suas produções, principalmente no que diz respeito à forma como eles pensavam o corpo. Acreditamos que, apesar dos distanciamentos que podem ser claramente percebidos entre os dois teóricos, é possível aproximá-los e, por vezes, colocá-los em diálogo, numa tentativa não só de compreender o legado por eles deixado como de ampliar a visão de corpo e corporeidade presente nos estudos atuais.

\section{Marcel Mauss}

Em sua obra de maior vulto, $O$ ensaio sobre a dádiva, Mauss desenvolveu o conceito de Fato Social Total (FST). Esta noção implica a compreensão de que, em qualquer realização do ser humano, podem ser encontradas as dimensões sociológica, psicológica e fisiológica. Esta tríplice abordagem só é possível de ser alcançada porque tais dimensões constituem uma unidade, quando encarnadas na experiência de qualquer indivíduo membro de determinada sociedade (Lévi-Strauss, 1974).

Foi com base nos mesmos princípios utilizados para elaborar a noção de FST que Mauss, mais tarde, em As técnicas do corpo, se referiu à noção de Homem Total (HT). 0 autor dedica esse ensaio especificamente ao tema corpo e aos modos como os homens, sociedade por sociedade, "servem-se de seus corpos". Levando-se em conta a época de sua produção, dado extremamente relevante neste caso, em que qualquer superação a respeito do tema se deparava com inúmeras limitações teóricas e, inclusive, de linguagem, a elaboração de Mauss sobre os usos do corpo sugere implicações atuais. Optamos por compreender a noção de "usos do corpo", sem nos tornarmos reféns da visão utilitarista a que o termo possa remeter. Não pretendemos negar o possível vácuo teórico presente numa concepção que, justamente pelos limites já citados, apresenta resquícios da concepção dualista, a qual separa o "ser" do "ter" um corpo. Lembremos que a intenção de Mauss era justamente superar tais entendimentos sobre o ser humano e sobre o corpo. É preciso lembrar, ainda, dos limites encontrados nas teorias atuais sobre o tema, as quais, mesmo após quase cem anos dos escritos de Mauss, apresentam resquícios de tal dualismo e parecem não encontrar a melhor maneira de superá-lo.

É a partir de outra noção presente no texto das "técnicas corporais" que percebemos um dos principais legados de Mauss: a noção de "imitação prestigiosa”. Mauss 
discorre sobre o imitar e o aprender gestos de pessoas que, de certa forma, obtiveram sucesso. Ao pensar no cotidiano das sociedades contemporâneas, podemos enumerar uma série de categorias que podem servir não só como parâmetros de sucesso (no sentido maussiano), mas como modelos a serem alcançados por pessoas que desejam se enquadrar em determinados padrões, como, por exemplo, ser magro, ser bonito, ser famoso, ser puro, ser habilidoso, ser forte, etc.

Ainda pensando em "usos do corpo", há que levar em conta a proximidade do termo com aquilo que Pierre Bourdieu pensa sobre o "habitus"². Inspirado, a princípio, no que Mauss afirma sobre o hábito, Bourdieu amplia o conceito e torna-o conhecido. É importante lembrar que, ao elaborar aquilo que entendemos por "habitus" em sua teoria, Bourdieu aproxima suas reflexões à noção de “incorporação". Para o autor, nós aprendemos pelo corpo, no qual a ordem social se inscreve por meio de confrontos permanentes. Nesse sentido, pensar em “incorporação” é entender que ela se dá por obra da razão prática (coletiva e individual). Segundo Wacquant (2002, p.118), fortemente influenciado pela teoria de Bourdieu, interiorizamos uma série de disposições inseparavelmente mentais e físicas ao longo do tempo. Para ele, a socialização adequada a algo ou a algum grupo depende da habituação dos gestos e dos comportamentos. Wacquant afirma que o "habitus" emerge da ordem de uma razão prática, que, "incrustada no fundo do corpo, escapa à lógica da escolha individual”. Sendo assim, o sentido prático orienta "escolhas" que não deixam de ser sistemáticas só por não serem deliberadas.

Influenciando a produção de inúmeros autores, a proposta de Mauss de pensar num ser humano de forma totalizante é expressiva. Tentando relacionar as esferas biológica, psicológica e social, no que diz respeito ao que ele chamou de

2. É interessante lembrar, como exemplo, quando Bourdieu cita o caso do "criado do café", de Sartre (ver Bourdieu, 2009, p.88), para afirmar que as tradições são encarnadas nos corpos e nas vestes "habitadas por um certo habitus". Bourdieu alerta para o fato de que a história inscrita no corpo do criado demonstra um "habitus", uma tradição. No entanto, isso não significa que ele tenha aprendido a ser criado de café imitando outros criados de café, como se fossem modelos constituídos. Ele se identifica com a função de criado de café, como a criança se identifica com o seu pai (social) e adota, sem sequer precisar fingir, uma maneira parecida de se portar e que parece constituir o ser social do adulto perfeito. "usos do corpo", o autor defende a ideia de que toda técnica corporal é tradicional. Tentando relativizar a ênfase biológica que sempre recaiu sobre o corpo, o autor considera-o como uma construção cultural própria de cada sociedade, já que seres humanos diferentes utilizam seu corpo de formas diferenciadas (Mauss, 1974). Para ele, o corpo humano é, ao mesmo tempo, "matéria-prima" e "ferramenta" da cultura, o que o leva a afirmar que não é possível encon- 
trar um modo natural no adulto. Para Mauss, os gestos mais "naturais" são fabricados por normas coletivas. Há uma construção social do corpo e do gesto, mas que se impõe de modo diferenciado a cada indivíduo, de acordo com suas condições de estar no mundo.

Nesse sentido, deparamo-nos com uma das maiores questões presentes no debate contemporâneo sobre o tema, ou seja, o modo como alguns pesquisadores vêm operando com visões deterministas sobre o corpo. A ideia de Mauss a respeito do corpo como matéria-prima e produtor da cultura pode gerar um tipo de entendimento no qual o corpo é determinado social ou culturalmente. De fato, estamos habituados a tecer críticas justamente à visão oposta, ou seja, aquela que opera partindo da ideia de um determinismo biológico e ignora ou nega as implicações da vida social na educação e na construção dos corpos.

Com relação a essas visões deterministas, Pierre Bourdieu (2003, p.32) fala sobre a evidência da "individuação biológica" que nos impede de ver que a sociedade existe sob formas inseparáveis. Para o autor, há

[...] de um lado as instituições que podem revestir a forma de coisas físicas, monumentos, livros, instrumentos etc.; do outro, as disposições adquiridas, as maneiras duradouras de ser ou de fazer que encarnam em corpos (e a que eu chamo de "habitus"). 0 corpo socializado (aquilo a que se chama o indivíduo ou a pessoa) não seopõeà sociedade: éuma de suas formas de existência.

Não que a teoria de Mauss se apresente de forma determinista, mas é nesse sentido que entendemos que Merleau-Ponty incrementa o debate. Um possível diálogo no qual acrescentássemos as contribuições deste autor minimizaria reflexões deterministas e ampliaria a visão e o modo como pensamos o corpo nas pesquisas atuais.

\section{Maurice Merleau-Ponty}

Em sua obra Signes, de 1960, Merleau-Ponty publicou o capítulo intitulado "De Mauss a Claude Lévi-Strauss", em defesa da ocupação da cadeira de Antropologia Social por Lévi-Strauss, no Collège de France. Trata-se do reconhecimento do autor à importância que a Antropologia teve, ao esclarecer o papel do observador em sua relação com o seu objeto pesquisado, que é também sujeito. Segundo Merleau-Ponty, 
após essa contribuição, não há mais que escolher entre o indivíduo e o coletivo. Há aqui a consideração da intersubjetividade, já que o objeto pesquisado não é um animal ou uma coisa inanimada, mas um ser humano, diferente em alguns aspectos, mas tão humano quanto o pesquisador. Para o autor, o que interessa da Antropologia ao filósofo "é precisamente o tomar o homem como é, em sua situação afetiva de vida e conhecimento" (Merleau-Ponty, 1980, p.205).

Nesse caso, é interessante perceber que, mesmo sendo fenomenólogo e reconhecido por sua teoria da percepção, na qual o corpo é pleno de subjetividade, Merleau-Ponty reconhece a intersubjetividade marcada numa "condição corpórea” que se dá entre ações individuais e coletivas. A influência de Mauss e Lévi-Strauss na fenomenologia de Merleau-Ponty torna-se imprescindível, justamente por promover a dissolução de uma ideia de sentido que é apenas interna. Na medida em que Merleau-Ponty busca romper com a oposição entre natureza e cultura, ele elabora uma noção de corporeidade que considera, a princípio, o corpo (carne) como modo de apreensão sensivel do significado, o qual não é possível de ser reduzido à ordem da natureza humana. Se, para ele, as percepções e as apreensões do mundo estão fundamentadas num corpo biológico, concomitantemente elas são definidas pela sociedade e pela cultura específica de cada grupo.

Considerando a estrutura psicológica, Merleau-Ponty aponta, em Fenomenologia da percepção, que o corpo é o local da experiência com o outro e com o mundo. $\mathrm{O}$ corpo possibilita e inaugura a existência e a presença do ser no mundo. Em $\mathrm{O}$ visível e o invisível, o autor trata o corpo como uma realidade ontológica, enfatizando a experiência subjetiva encarnada que, passando pela consciência do ser permite a compreensão das inúmeras significações que organizam o esquema corporal (Merleau-Ponty, 1992).

Se, para Mauss, técnica e tradição são termos mais significativos, para Merleau-Ponty, a noção de carne se sobrepõe:

A carne não é matéria, não é espírito, não é substância. Seria preciso, para designá-la, o velho termo elemento, no sentido em que era empregado para falar-se da água, do ar, da terra e do fogo, isto é, no sentido de uma coisa geral, meio caminho entre o indivíduo espácio-temporal e a idéia, espécie de princípio encarnado que importa um estilo de ser em todos os lugares onde se encontra uma parcela sua (Merleau-Ponty, 1992, p.135). 
É nesse sentido que Furlan e Bocchi (2003) analisam o caráter corpóreo da significação. Os sentidos localizados na carne apontam para o gesto. Os autores apropriam-se da teoria de Merleau-Ponty, ao pensarem o gesto como movimento expressivo originário da linguagem. Afinal, para o autor, o gesto produz a comunicação na medida em que articula fala, corpo, percepção e expressão.

Merleau-Ponty diz que eu só consigo compreender a intencionalidade do outro - e sua atitude para comigo - porque através do meu corpo posso torná-la minha. Assim, encontramos em seu pensamento um lugar especial para o corpo, a ele é atribuída uma potência expressiva que lhe é imanente: o corpo é intencionalidade que se exprime, e que secreta a própria significação (Furlan; Bocchi, 2003, p.449).

Nesse caso, o corpo é tanto expressão de uma conduta como criador de sentido, uma vez que, antes da expressão, há apenas uma ausência. 0 que preenche as lacunas dessa ausência é o gesto. A presença do outro se faz pela carne. Merleau-Ponty afirma que

um outro é esse corpo animado de todos os tipos de intenções, sujeito de ações ou afirmações das quais me lembro e que contribuem para o esboço de sua figura moral para mim. [...] e a aparência total desse corpo parece-nos conter todo um conjunto de possibilidades das quais o corpo é a presença propriamente dita (Merleau-Ponty, 2004, p.43).

O corpo, para o autor, não só expressa a presença do outro como nos torna conscientes da nossa presença. Pois, para Merleau-Ponty, só sentimos que existimos depois de termos entrado em contato com outros. Para ele, nossa consciência de nós mesmos se dá no retorno, após termos "frequentado" o outro.

A fenomenologia, em sentido amplo, e as contribuições de Merleau-Ponty, em particular, abriram diversas perspectivas de análise no pensamento posterior e ainda são substratos metodológicos e conceituais, como no caso da filosofia francesa contemporânea. Maffesoli (1998, p.116-117) supõe a "descrição" como uma herança fenomenológica que subsidia a elaboração de uma “razão sensível”, quer por colocar em uma mesma organicidade sujeito e mundo, quer por ter sido certo idealismo clás- 
sico substituído, desde Husserl, por uma “promoção da idéia de horizonte”, na qual a perspectiva causal é superada pela análise descritiva do ser no mundo. Em sentido próximo, Onfray (2006, p.68) advoga por uma "razão corporal”, método apresentado por ele como alternativo, ao saber que "desce dos céus", pois é encontrado nas paixões, na saúde e na doença, na força e na fraqueza da carne. Para Lipovetsky (2004), os tempos atuais exigem compreensão dos próprios movimentos do homem na cultura, extremamente efêmeros, não dependentes exclusivamente nem das tradições, nem da moral, mas de fenômenos muito mais cambiantes, como a moda, instituindo uma lógica só compreensível no próprio devir social. Por diversos caminhos, o método fenomenológico se faz presente na análise contemporânea e, como o corpo e a percepção parecem assumir papéis de destaque em muitas delas, a obra de Merleau-Ponty reafirma sua atualidade.

\section{Aproximações e diálogos possíveis}

Podemos constatar que tanto Merleau-Ponty quanto Mauss, por caminhos diversos, encontraram na facticidade do ser humano a solução para o impasse em que a ciência se colocou a partir do dualismo cartesiano. Porque o ser humano, em sua constante ação no mundo, é mais do que um ser dotado de individualidade psíquica e é mais do que um organismo puramente biológico. Enquanto Mauss trata do "fato social total" como composto sincronicamente das dimensões psicológica, fisiológica e sociológica e sintetizado na experiência individual do ser humano, Merleau-Ponty trata de um "sujeito encarnado", de um "ser no mundo", de um mundo vivido e não apenas pensado.

Entendemos melhor agora por que os dois autores dedicam parte de sua obra ao tema corpo. Ora, para Merleau-Ponty o corpo é justamente o que encarna o sujeito no mundo, que mediatiza a relação do sujeito com ele. 0 autor insiste que "[...] o corpo é o veículo do ser no mundo" (Merleau-Ponty, 1971, p.94).

Mauss aborda o corpo como dotado, além do componente biológico - patrimônio universal do ser humano - , do aspecto psicológico e do aspecto sociológico. Um gesto humano implica disposições fisiológicas, mas é também composto pela individualidade psicológica, que diferencia o realizador do gesto de outra pessoa, e está relacionado a uma sociedade que dá determinada significação a esse movimento.

Há de se perguntar se Merleau-Ponty deixou de lado o nível sociológico destacado no corpo por Mauss. Apesar de, muitas vezes, ser criticado por isso, Merleau-Ponty 
não esquece o aspecto social inerente ao corpo. Quando afirma que a aquisição de um hábito "[...] é a apreensão motora de uma significação motora” (Merleau-Ponty, 1971, p.154), ele está considerando que o ser humano, por meio de seu corpo, aprende determinados movimentos que são significativos num contexto social específico. $\mathrm{O}$ autor afirma que "o corpo compreendeu e o hábito foi adquirido quando se deixou penetrar por uma nova significação, quando assimilou um novo centro significativo" (Merleau-Ponty, 1971, p.158).

Merleau-Ponty compara o corpo a uma obra de arte, justamente por se constituir num "nó de significações vivas". Mauss, provavelmente, partilharia dessa comparação. $O$ que parece diferenciar Merleau-Ponty de Mauss não é a definição de corpo, mas a forma de analisar o ser humano no mundo. Em Merleau-Ponty, há um movimento que parte do sujeito encarnado, dotado de um corpo próprio, em direção à vinculação social. Já em Mauss, o movimento parece ser contrário, parte da construção social específica de um corpo, em direção a uma síntese individual. Em Merleau-Ponty, o sujeito encarnado é passível de significação. Em Mauss, a sociedade está encarnada na experiência individual. É claro que essa distinção do percurso investigativo, meramente formal, é solucionada como abordagem orgânica tanto por um como por outro autor. Em Merleau-Ponty, por exemplo, o papel das essências é fundamental. Mas, diferentemente de uma razão abstrata, como a presente na tradição filosófica, a essência é encarnada no real, tal como lemos em Reale e Antiseri (2003, p. 615, grifos dos autores):

A fenomenologia [para Merleau-Ponty] é o "estudo das essências: por exemplo, a essência da percepção e a essência da consciência”, mas "a fenomenologia também é uma filosofia que repõe as essências na existência e pensa que não se pode compreender o mundo e o homem senão com base na sua 'faticidade'".

Merleau-Ponty parece estar mais interessado no movimento que ocorre a partir de uma experiência fenomenológica. Já Mauss parece ter atentado mais para o que foi objetificado a partir da experiência. Portanto, pensar nas diferenças básicas que marcam estes autores parece-nos que significa também compreender que a noção de subjetividade provém de pontos de vista distintos em cada um deles. Enquanto Mauss entende o ser humano pelo viés da coletividade - não nega a individualidade, mas a assume como algo fundamental para pensar o ser humano -, Merleau- 
-Ponty tem como tema de fundo de sua filosofia a relação consciência-mundo (Reale; Antiseri, 2003). Não nega a relação entre indivíduo e coletividade: ao contrário, considera o movimento de significação como algo construído pela coletividade, possibilitado pela vida social.

Um diálogo entre os autores ampliaria a visão sobre corpo e corporeidade, não somente entendendo que as diferenças teóricas de ambos podem ser superadas, uma vez que os autores também dialogam pelas semelhanças. Tanto para Mauss como para Merleau-Ponty, o corpo, dotado de significados socialmente partilhados, é a expressão de uma dada sociedade. É justamente nesse diálogo que percebemos a possibilidade de ampliação daquilo que pensamos sobre o corpo e sobre o ser humano. Ao possibilitar que a discussão sobre corpo seja ampliada de um referencial unicamente biológico para uma perspectiva mais relacional, que considera o ser humano como um ser no mundo e para o mundo, as diferenças entre os autores aparecem minimizadas.

Baseados em pressupostos que se originam no tipo de teoria desenvolvida por Mauss e Merleau-Ponty, mesmo tendo o caminho desviado em algum momento, inúmeros autores utilizam esse tipo de diálogo para problematizar questões e pesquisas mais recentes.

Almeida (2004) reporta que, na década de 1970, Mary Douglas desenvolveu os argumentos de Mauss para falar sobre os "símbolos naturais" e considera que o "durkheimianismo" de Douglas desemboca na elaboração de uma antropologia do corpo baseada em análises dos usos metafóricos dos símbolos na reprodução da ordem social, o que resulta num tipo de análise que acaba por definir sistemas de classificação. Almeida ainda aponta que Michel Jackson (1989), contrariando a ideia de cultura como algo superorgânico, afirma que a subjetividade está localizada no corpo. Com base nas concepções fenomenológicas, ele contraria a posição simbolista e diz que o corpo não se limita a refletir a sociedade (Almeida, 2004). No sentido oposto ao de Durkheim e Douglas, o que Jackson está propondo é que possamos compreender que aquilo que permite a vida em comum entre os seres humanos se dá num envolvimento que é, ao mesmo tempo, prático e sensual. Nesse sentido, Jackson contraria a ideia de corpo como mero local de inscrição. Isso demonstra, de certa forma, uma ampliação e superação de visões deterministas sobre o ser humano e sobre o corpo. De modo geral, podemos dizer que o que Jackson realiza é um diálogo entre concepções fenomenológicas e socioantropológicas. 
Na perspectiva estrutural de Douglas, há o reconhecimento de que o corpo não é determinado de forma absoluta pelo social. Mas, ao que parece, as teorias sobre corpo não têm estabelecido, de maneira suficiente, o diálogo entre os domínios do biológico e do social. Como se num "cabo de guerra" estivesse, de um lado, o determinismo biológico e, do outro, o determinismo social. 0 fato é que, para utilizar esta metáfora, é preciso entender que, em algum momento, a corda vai pender para um dos lados e, nessa briga de forças, continuaremos a operar com conceitos limitados por um vazio teórico.

Outra tentativa de superar esse vazio foi a do antropólogo Thomas Csordas, reconhecido por sua "antropologia da corporeidade". No prefácio de seu livro Corpo, significado e cura, Steill (2008), que é o principal propagador da obra de Csordas no Brasil, comenta que a perspectiva de Csordas é ir além do significado. 0 que este pretende é compreender a experiência do que significa ser humano, enquanto um corpo no mundo. $\mathrm{O}$ autor defende que a abordagem da corporeidade está para além da representação e do discurso, sem, no entanto, incluir essas dimensões. Combinando de forma produtiva os trabalhos de Merleau-Ponty sobre corpo e percepção e os trabalhos de Bourdieu sobre o "habitus", Csordas visa a colapsar as dicotomias corpo-mente, sujeito-objeto e outras. Embora o autor parta da experiência religiosa, principalmente da compreensão dos fenômenos de cura, para desenvolver seus argumentos, sua teoria pode ser desdobrada para inúmeras pesquisas de outro cunho, que não o religioso, incluindo reflexões que visem à compreensão de questões relacionadas ao paradigma da corporeidade.

Um dos principais argumentos de Csordas é que dimensões subjetivas presentes no movimento, ou seja, na experiência corpórea, escapam ao discurso; portanto, não podem reduzir-se a ele. Interessante notar que, ao elaborar seu "paradigma da corporeidade", ele traz para o texto noções fundamentais do pensamento fenomenológico e aponta como ele pode dialogar com a teoria sociológica de Bourdieu. Ao citar Bourdieu, ele não se esquece de fazer referência a Mauss e ao modo como a noção de "habitus" diz respeito ao pensamento maussiano.

Paralelamente ao objetivo de Merleau-Ponty de deslocar o estudo da percepção dos objetos para o processo de objetificação, o propósito de Bourdieu é ir além da análise do fato social como um opus operantum, para a análise do modus operandi da vida social. Sua estratégia é colapsar as dua- 
lidades de corpo-mente e signo-significação no conceito de "habitus". Esse conceito foi introduzido por Mauss em seu ensaio seminal sobre as técnicas do corpo, para referir-se à soma total de usos culturalmente padronizados do corpo numa sociedade. Para Mauss, foi um modo de organizar o que de outra maneira seria uma miscelânea de comportamentos culturais padronizados, merecendo apenas um parágrafo de elaboração. Ainda assim, Mauss antecipou como um paradigma da corporeidade pode mediar dualidades fundamentais [...] em sua declaração de que o corpo é simultaneamente o objeto original sobre o qual o trabalho da cultura se desenvolve e a ferramenta original com a qual aquele trabalho se realiza. É, de uma vez, um objeto da técnica, um meio técnico e a origem subjetiva da técnica (Csordas, 2008, p.109).

Partindo originalmente da noção de "hábito" de Mauss, o que Bourdieu fez foi inaugurar a ideia de um corpo socialmente informado, com seus gostos e desgostos, ou, em uma palavra, com seus sentidos, o que veio a ser, posteriormente, utilizado com frequência por inúmeros pesquisadores (como é o caso de Csordas), que, de forma semelhante, buscam romper com as dicotomias e os dualismos nos estudos sobre corpo.

Poderíamos, ainda, citar outros exemplos de como o diálogo entre tais concepções pode ser produtivo na busca da compreensão sobre o que é o corpo e o ser humano. 0 fato é que, para a ampliação de um debate a respeito da corporeidade, parece evidente considerarmos o "salto" possibilitado por autores como Mauss e Merleau-Ponty e, mais do que evidente, parece necessária uma tentativa de operar com um tipo de pensamento que coloque em diálogo teorias do mesmo gênero, as quais deixem de negar determinadas esferas humanas em detrimento de outras. Afinal, se o corpo é condição primeira da relação do homem com o mundo e se experiências corpóreas escapam ao discurso, demonstrando dimensões subjetivas do que significa ser humano, por outro lado, "nosso contato conosco sempre se faz por meio de uma cultura, pelo menos por meio de uma linguagem que recebemos de fora e que nos orienta para o conhecimento de nós mesmos" (Merleau-Ponty, 2004, p.49). Sendo assim, considerar as dimensões individuais, sem negar as coletivas, e vice-versa, é compreender, como afirma Merleau-Ponty (2004), p.50), "que não há vida em grupo que nos livre do peso de nós mesmos, que nos dispense de ter uma opinião; e não existe vida 'interior’ que não seja como uma primeira experiência de nossas relações com o outro". 


\section{Referências bibliográficas}

ALMEIDA, M. V. O corpo na teoria antropológica. Revista de comunicação e linguagem, Lisboa, n. 33, p. 49-66, 2004.

BOURDIEU, P. A economia das trocas simbólicas. São Paulo: Perspectiva, 2009.

BOURDIEU, P. Questões de Sociologia. Lisboa: Fim de Século, 2003.

CHAUI, M. Prefácio. In: MERLEAU-PONTY, M. Os pensadores: textos selecionados. São Paulo: Abril Cultural, 1980.

CSORDAS, T. Corpo, significado, cura. Porto Alegre: Editora da UFRGS, 2008.

FURLAN, R.; BOCCHI, J. C. O corpo como expressão e linguagem em Merleau-Ponty. Estudos de Psicologia, Natal, n. 8, p. 445-450, 2003.

LÉVI-STRAUSS, C. Introdução à obra de Marcel Mauss. In: MAUSS, M. Sociologia e Antropologia. São Paulo: EDU/EDUSP, 1974. v. 2.

LIPOVETSKY, G. Os tempos hipermodernos. 3. ed. São Paulo: Barcarolla, 2004.

MAFFESOLI, M. Elogio da razão. 2. ed. Petrópolis, RJ: Vozes, 1998.

MAUSS, M. Sociologia e Antropologia. São Paulo: EDU/EDUSP, 1974. v. 2.

MERLEAU-PONTY, M. Conversas-1948. São Paulo: Martins Fontes, 2004.

MERLEAU-PONTY, M. De Mauss a Claude Lévi-Strauss. In: MERLEAU-PONTY, M. Os pensadores: textos selecionados. São Paulo, Abril Cultural, 1980.

MERLEAU-PONTY, M. Fenomenologia da percepção. Rio de Janeiro: Freitas Bastos, 1971.

MERLEAU-PONTY, M. O visível e o invisível. 3. ed. São Paulo: Perspectiva, 1992.

MERLEAU-PONTY, M. Signes. Paris: Gallimard, 1960.

ONFRAY, M. La puissance d`exister. Paris: Grasset, 2006.

REALE, G.; ANTISERI, D. História da filosofia. 6. ed. São Paulo: Paulus, 2003. v.3.

STEILL, C. A. Prefácio. In: CSORDAS, T. Corpo, significado, cura. Porto Alegre: Editora da UFRGS, 2008.

WACQUANT, L. Corpo e alma: notas etnográficas de um aprendiz de boxe. Rio de Janeiro: Relume Dumará, 2002.

Recebido em 21 de setembro de 2011 e aprovado em 18 de abril de 2012. 
